\title{
Step-Up and Step-Down Treatment Approaches for COPD: A Holistic View of Progressive Therapies
}

\author{
Jose Luis López-Campos (D) \\ Laura Carrasco Hernández \\ Borja Ruiz-Duque \\ Rocio Reinoso-Arija \\ Candelaria Caballero-Eraso \\ 'Unidad Médico-Quirúrgica de \\ Enfermedades Respiratorias, Instituto de \\ Biomedicina de Sevilla (IBiS), Hospital \\ Universitario Virgen del Rocío/ \\ Universidad de Sevilla, Seville, Spain; \\ ${ }^{2}$ Centro de Investigación Biomédica en \\ Red de Enfermedades Respiratorias \\ (CIBERES), Instituto de Salud Carlos III, \\ Madrid, Spain
}

\begin{abstract}
Recent advances in inhaled drugs and a clearer definition of the disease have made the task of managing COPD more complex. Different proposals have been put forward which combine all the available treatments and the different clinical presentations in an effort to select the best therapeutic options for each clinical context. As COPD is a chronic progressive disease, the escalation of therapy has traditionally been considered the most natural way to tackle it. However, the notion of COPD as a constantly progressing disease has recently been challenged and, in specific areas, this points to the possibility of a deescalation in treatment. In this context, the clinician requires simple, specific recommendations to guide these changes in treatment in their daily clinical practice. To accomplish this, the first step must be a correct evaluation and an accurate initial preliminary diagnosis of the patient's condition. Thereafter, the first escalation in therapy must be introduced with caution as the disease progresses, since clinical trials are not designed with clinical decision-making in mind. During this escalation, three possibilities are open to change the current treatment for a different one within the same family, to increase non-pharmacological interventions or to increase the pharmacological therapies. Beyond that point, a patient with persistent symptoms represents a complex clinical scenario which requires a specialized approach, including the evaluation of different respiratory and non-respiratory comorbidities. Unfortunately, there are few de-escalation studies available, and these are mainly observational in nature. The debate on de-escalation in pharmacological treatment, therefore, involves two main discussion points: the withdrawal of bronchodilators and the withdrawal of inhaled steroids. Altogether, the scheme for modifying treatment must be more personalized than just adding molecules, and the therapeutic response and its conditioning factors should be evaluated at each step before proceeding further.
\end{abstract}

Keywords: COPD, escalation of treatment, pharmacological therapies, precision medicine

\section{Introduction}

In recent decades, advances in inhaled drugs have notably expanded the therapeutic options available for treating chronic obstructive pulmonary disease (COPD). Additionally, the implementation of high-throughput technology and big data analysis have created better opportunities to describe the signs and symptoms of the disease. $^{1,2}$ Consequently, the task of managing COPD correctly has become more complex and there have been calls for a more simple and realistic approach. ${ }^{3}$ Different proposals have been put forward combining all the available treatments and different clinical presentations in an effort to select the best therapeutic options for each clinical context. ${ }^{4}$ Some proposals are based on different key variables, as in the Global Initiative for Obstructive Lung Disease (GOLD) documents. ${ }^{5}$ Others
Correspondence: Jose Luis López-Campos Unidad Médico-Quirúrgica de Enfermedades Respiratorias, Instituto de Biomedicina de Sevilla (IBiS), Hospital Universitario Virgen del Rocío, Avda. Manuel Siurot, s/n, Seville, $4|0| 3$, Spain

Tel +34 955013166

Email lopezcampos@separ.es 
have proposed a phenotype-based approach which has also gained popularity via the Spanish Guidelines for COPD (GesEPOC). ${ }^{6}$ Although both initiatives have benefits and drawbacks, ${ }^{7,8}$ they provide an opportunity for clinicians to manage COPD more successfully in their daily clinical practice. Nowadays, at the start of this new decade, COPD management has progressed to the stage where specific patient-based recommendations can be provided. ${ }^{9}$

As COPD is a chronic progressive disease, escalation of therapy has been traditionally been considered the natural step in its treatment. However, the notion of COPD as a constantly progressing disease has been recently challenged, ${ }^{10,11}$ and this presents the chance for deescalation of treatment in specific scenarios. Accordingly, clear guidelines are required to understand the different clinical scenarios and how to escalate and de-escalate therapies at the patient level. In this paper, we would like to review the main studies regarding the selection of treatments for COPD. Our aim is to help clinicians in their day-to-day clinical decision-making by considering all the possible options and focusing specifically on the patient.

\section{Controversies in the Rationale Behind Clinical Decisions Making}

Before we begin to unravel the different clinical options and the determinants that condition clinical decisionmaking in COPD, a brief critical reflection is required to set the scenario on which to base the clinical discussion. In this debate, the main problem is that the available information comes basically from clinical trials designed and carried out by pharmaceutical companies. It is important to note that clinical trials with drugs are designed and conducted under strict conditions according to the requirements of evaluation agencies, mainly the US Food and Drug Administration and the European Medicines Agency. The purpose of these trials is, therefore, not to help clinical decision-making, but to gain approval of medicines by health agencies. If we take into account the different phases of pharmacological development, ${ }^{12}$ it is not really until the end of the clinical development, in Phase IV, that the specific response of patients to a certain therapy can begin to be evaluated. This is a very late stage in the process of drug development, but it is precisely this stage that helps clinicians in their real-life decision-making.

In fact, while the routine assessment of clinical trial results, in terms of the average response between different treatment groups, gives us a very clear idea of how the drug will perform in a particular clinical context, it tells us very little about how the individual patient reacts when receiving the treatment. Another relevant related concept is the Minimal Clinically Important Difference that could be used to decide escalation or de-escalation treatment. ${ }^{13}$ Interestingly, this concept also represents an average response, trying to summarize a complex variable response. In epidemiology, this discrepancy is termed the "ecological fallacy" and represents one of the major challenges in evidence-based medicine. ${ }^{14,15}$ Therefore, when clinical practice guidelines recommend a certain treatment for a patient in a particular clinical situation based on clinical trials, they cannot really guarantee that this treatment is right for a particular patient. The best they can do is to state that this patient is more likely to respond to a certain therapeutic option. This nuance is important, because despite the very strong claims which are often made for certain drugs in disease management, it is hardly surprising that they may not be as successful in specific patients in real life. In other words, studies tell us that a certain treatment option is more likely to work, which does not mean that it actually works for a specific patient in a specific clinical context. Subsequent studies by the company, competitors and independent researchers will include a broader population, and will gain better knowledge about effect, eg responders and non-responders in relation to other COPD drugs, and about safety.

For this reason, those responsible for developing clinical practice guides usually recommend clinicians to take the guidelines as only a general reference and to adapt them to the real situation of each patient. This is tantamount to saying that the guide document describes how to treat the average patient, but that it is of no use in daily clinical practice. Interestingly, current clinical audits have revealed that a number of recommendations are not fulfilled in daily clinical practice, which does not imply that this clinical practice is not correct, ${ }^{16-18}$ since there are a considerable number of factors that naturally condition clinical practice which are not considered in clinical trials and therefore in the clinical guidelines' recommendations. ${ }^{19}$ Therefore, the escalation and de-escalation strategies for chronic diseases are based on the fact that the evidence available for treating individual patients is alarmingly scarce, since clinical trials do not evaluate individual patients, but cohorts. Having said that, in the following sections we will attempt to present a practical approach to the scaling and de-escalation of the treatment in COPD patients. 


\section{First Things First: Does the Patient Have COPD?}

In this context of uncertainty, one of the first problems we face before discussing changes in treatment is the certainty of the COPD diagnosis. Regardless of the debate about the over- or under-diagnosis of COPD, ${ }^{20}$ when a patient goes to the doctor for chronic respiratory symptoms, the clinician must decide what the patient's initial diagnosis is. At this point, clinicians have to deal with the ambiguity of the clinical presentation, since the clinical expression of airway diseases has a very limited number of symptoms. In all patients suffering from an airway disease (eg COPD, asthma or bronchiectasis), there is dyspnea, coughing, expectoration, chest tightness and chest noises to varying degrees, with limitation of daily activities as a consequence. Therefore, the diagnosis is reached more through the temporal distribution and variability of the disease over time than by the presence of particular symptoms.

Consequently, it is crucial to establish an accurate diagnosis from the beginning. In particular, clinicians must differentiate whether the patient is suffering from COPD or asthma. We know that both diseases have similar clinical expressions and also share many inhaled treatments. However, although the inhaled drugs are similar, the escalation of treatment for the two clinical conditions is completely different. While asthma is an inflammatory disease which is treated with inhaled corticosteroids (ICS) together with long-acting bronchodilators (LABD), COPD is an obstructive disease that is treated with LABD, together with ICS in specific cases. Therefore, treatment for the two conditions involves similar drugs but with a different therapeutic strategy. Accordingly, the first challenge will be to ensure that the patient does indeed have COPD.

At the patient's first visit, it is often difficult to identify the disease and differentiate between COPD and asthma for several reasons. Firstly, although in many cases a specific clinical pattern can be clearly identified, the patient sometimes needs to be monitored over a period of time to assess the therapeutic response before establishing a definitive diagnosis. ${ }^{21}$ Secondly, there is often a discrepancy between the clinical presentation and the results of the complementary tests which are supposed to confirm the suspected diagnosis. This discrepancy is especially striking in asthma, since confirmation of asthma in a given clinical context can
Table I Clinical Presentation and Complementary Tests for Asthma and COPD

\begin{tabular}{|c|c|c|}
\hline & Asthma & COPD \\
\hline $\begin{array}{l}\text { Clinical } \\
\text { context }\end{array}$ & $\begin{array}{l}\text { Dry cough, with chest } \\
\text { tightness and/or recur- } \\
\text { rent wheezing } \\
\text { - Nighttime predominance } \\
\text { of symptoms } \\
\text { - Bronchospasms with clear } \\
\text { triggers: non-specific } \\
\text { exposure, seasonal aller- } \\
\text { gies, hyperventilation } \\
\text { (exercise, laughter) } \\
\text { - Other atopic traits: rhino- } \\
\text { conjunctivitis, dermatitis } \\
\text { - Recognized allergies }\end{array}$ & $\begin{array}{l}\text { - } \text { Chronic dyspnea } \\
\text { - Cough \& expectoration } \\
\text { - Limitation in daily activities }\end{array}$ \\
\hline $\begin{array}{l}\text { Confirmatory } \\
\text { tests }\end{array}$ & $\begin{array}{l}\text { - Bronchodilator test: FEVI } \\
\text { or PEF } \\
\text { - Peak flow } \\
\text { - Fractional exhaled nitric } \\
\text { oxide } \\
\text { - Bronchial hyperrespon- } \\
\text { siveness test } \\
\text { - Oral or inhaled corticos- } \\
\text { teroid test }\end{array}$ & $\begin{array}{l}\text { - Post-bronchodilation } \\
\text { obstruction }\end{array}$ \\
\hline
\end{tabular}

be achieved using different complementary tests, whereas in COPD, only a post-bronchodilator spirometry is needed (Table 1).

In this context, over the last few decades, the term "asthma-COPD overlap (ACO)" has been coined. ${ }^{22,23}$ Although widely used by the scientific community, the concept of ACO has never been clearly defined, and many different terms and criteria have been proposed. ${ }^{24,25}$ Interestingly, the prevalence of ACO varies enormously depending on the diagnostic criteria used. ${ }^{26}$

With the experience accumulated and the different studies conducted in recent years, we can confidently state that the term ACO conceals two different, closely interlocking concepts. On the one hand, an ACO case could refer to a patient who has both diseases and who, therefore, meets the diagnostic criteria for both clinical conditions (Table 1). On the other hand, an ACO case can also be a patient with one disease (COPD or asthma) whose illness, without meeting the criteria for the other disease, behaves in a similar way to the other. To put it simply, this asthma-like clinical behavior in COPD has been associated with blood eosinophil counts. ${ }^{5}$ Accordingly, since asthma is treated with ICS, several authors and guidelines have tried to associate the blood eosinophil count with an ICS positive treatment response. ${ }^{5,27}$ 
However, this association between the eosinophil count in the blood and asthma-like behavior or clinical response to ICS is somewhat controversial. ${ }^{28-31}$ Although guidelines were hastily published to recommend the use of the blood eosinophil count when selecting a treatment with ICS in specific COPD patients, a number of unanswered questions should be clarified before recommending their use as a routine marker in clinical practice. In fact, a recent study does not support the use of the blood eosinophil count as a reliable biomarker of the risk of exacerbation in COPD in a predominantly non-exacerbating population, suggesting a key role of the clinical context. ${ }^{28}$ Accordingly, different approaches have been proposed to use the blood eosinophil count more cautiously for selecting treatments by including the clinical context, ${ }^{32}$ persistence over time ${ }^{33}$ or the combination with exhaled biomarkers, ${ }^{34,35}$ which should further specify the patient's needs and make it more acceptable in the future.

While no better biomarkers are available, a better clinical approach would probably involve identifying either concomitant asthma or asthma-like behavior in COPD. Currently, the diagnosis of asthma is based on two conditions: a compatible clinical presentation and complementary tests that confirm the variability of the airway obstruction (Table 1). With these criteria, a $2 \times 2$ table could be constructed to show the presence/absence of these two criteria, before carrying out the diagnostic process described in Figure 1. These 4 possibilities (based on the clinical presentation and the result of the complementary studies) include the classic COPD, as well as two types of ACO. Type 1 ACO describes the patients with both diseases, whereas in Type 2 ACO the patient has one disease, but the clinical presentation is atypical (Figure 1). The immediate consequence of having concomitant asthma or asthma-like behavior is the use of ICS as part of the therapeutic strategy from the beginning. Needless to say, this is based on clinical judgement, since there are no clinical trials on how to treat a COPD patient who presents asthma-like behavior.

\section{The First Treatment Option: The First Controversy}

Consequently, the initial treatment should change (Figure 2) depending on the clinical presentation of Figure 1. Three key variables have been proposed as the main markers to guide therapy: the perception of dyspnea evaluated by the mMRC score, the number of exacerbations and hospitalizations in the previous year and lung function, as evaluated by postbronchodilator forced expiratory volume in 1 second $\left(\mathrm{FEV}_{1}\right)^{5}$ Since patients seeking help are normally

\section{Initial diagnosis}

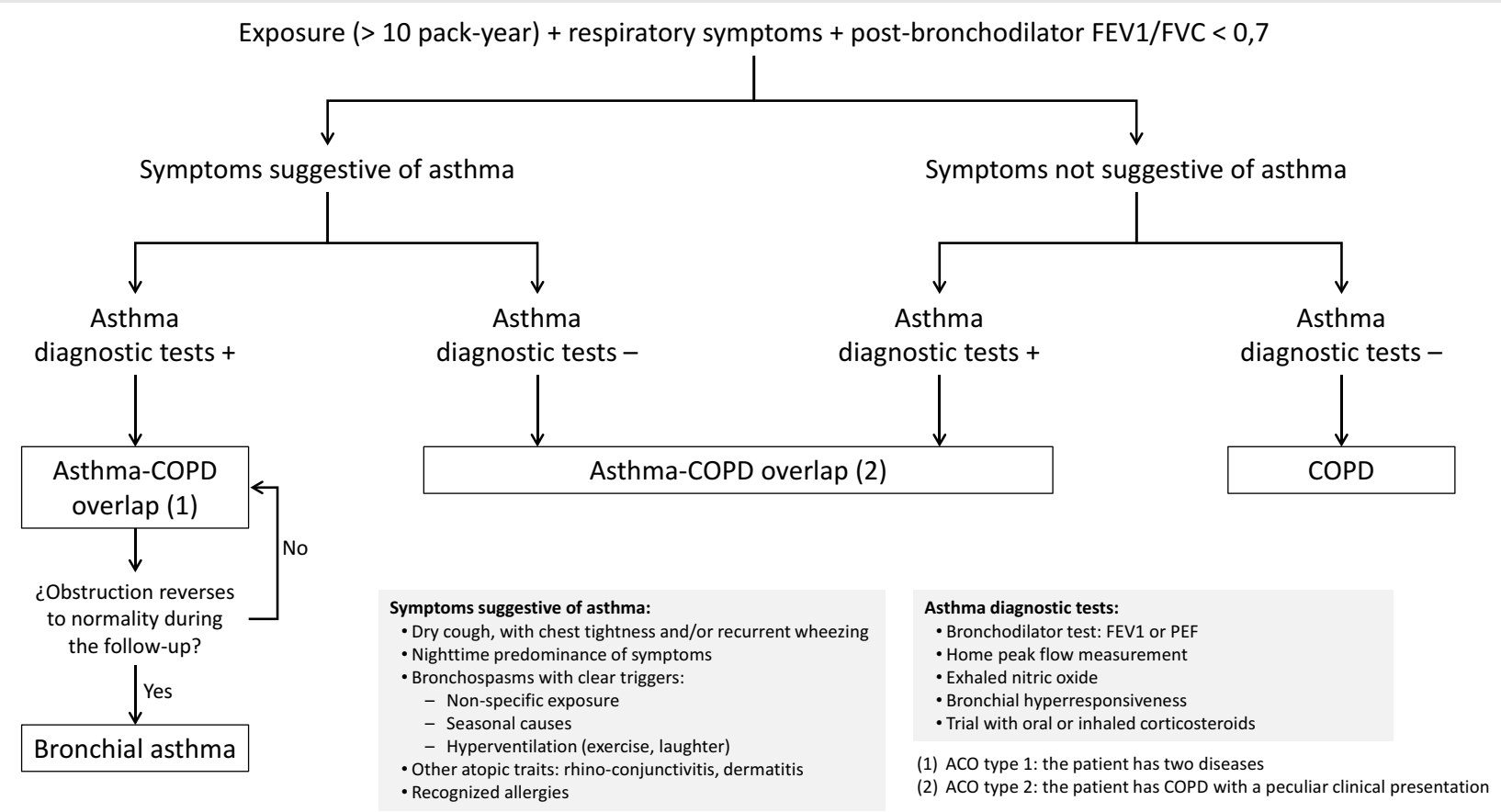

Figure I Diagnostic possibilities between COPD and asthma. 


\section{Initial therapeutic approach}

Low clinical impact if all of the following are present:

- Dyspnea mMRC 0-1

- No major limitations daily activities

- Exacerbations 0-1

- Hospitalizations 0

Figure 2 Initial therapeutic approach for COPD.

symptomatic, lung function and previous exacerbations can be selected to identify different patient types to propose the first treatment. Of these, lung function has been shown to markedly improve after double bronchodilation for all combinations. ${ }^{36}$ Therefore, it would be reasonable to advise that these cases should start by receiving one LABD, while cases with more pronounced lung function impairment should start by receiving two LABD instead of a single bronchodilation. Although different cutoffs have been identified in observational studies, ${ }^{37,38}$ the limit to define severe lung function impairment has been arbitrarily set at $50 \%$ or 1 $\mathrm{L}$ in post-bronchodilator $\mathrm{FEV}_{1}$. On the other hand, the patients' previous exacerbation history may well influence the different types of bronchodilators, whose effectiveness in the prevention of exacerbations has been shown to vary. ${ }^{39,40}$ Likewise, for the reasons explained above, patients with ACO must be treated using a different approach, including ICS in the therapeutic plan. Altogether, the decision about the initial therapy would probably rely on lung function impairment and the risk of exacerbations, as suggested in Figure 2.

\section{Initial Stepping Up from Initial Treatment}

After the selection of the initial treatment, this must be carefully evaluated to monitor the initial therapeutic response as well as the tolerance. The first unresolved question is the time that must be spent in active treatment in order to evaluate a particular patient's therapeutic response and tolerance. This first assessment must be made early on, as the inhaled drugs begin to work from the moment they are first inhaled. These effects are more immediate with bronchodilators in the first days after starting treatment, when improvements in lung function and symptoms have been reported. ${ }^{41}$ However, the preventive effect of LABDs and ICS on exacerbation risk may require a longer time to evaluate. Finally, we must also add to the equation the resources available to evaluate all first-therapy COPD patients. Altogether, although there is no consensus over the ideal evaluation time, a period of 3 months may be considered sufficient to observe the clinical impact of a first inhaled treatment (Figure 2). The evaluation of the control status at each clinical visit provides relevant prognostic information about the risk of an adverse progression in the coming months, since a lack of control is a warning signal that should prompt investigation and action. ${ }^{42}$ For example, continuous prospective evaluation is required in COPD patients since the impact on physical activity over time is heterogeneous and decliners cannot be predicted at baseline. ${ }^{43}$ Meanwhile, the patient should keep in touch with the health center in 
case any adverse effects occur during these first weeks of treatment.

In the first assessment after this period of time, the clinical and functional effectiveness should be evaluated in terms of symptoms and exacerbations, daily activities and lung function. Here, we can classify patients as low-impact cases if they do not have high dyspnea, and have no limitations in daily activities, few exacerbations and no hospitalizations, as well as maintaining correct lung function (Figure 2). Accordingly, they should be considered as high-impact if any of these criteria are not met. This concept is analogous to that proposed by the Spanish COPD guidelines (GesEPOC), recently updated for $2021 .^{6}$ This classification between high and low impact (or high and low risk, according to GesEPOC terminology) is extremely useful, since it identifies subjects who do not need an intensification of treatment and for whom a de-escalation could even be considered, as will be discussed later.

In high-impact patients, it is imperative to verify the correct inhalation technique, adherence to treatment, the appearance of adverse effects and satisfaction with the inhalation device before proceeding with escalation of the inhalation device. ${ }^{44}$ While this may seem obvious, the percentage of cases in which this assessment is either not made or not recorded is truly alarming. ${ }^{17,18,45}$ In patients diagnosed with COPD who are given suitable treatment, with good inhalation technique, good tolerance to treatment, correct compliance and adequate satisfaction with the inhalation device and who, furthermore, persist with a high clinical impact, a change in treatment needs to be planned. Here, there are at least three questions, for which we do not always have an answer.

\section{Question I: Should We Always Escalate?}

The first issue with this kind of patient is whether to scale or change the molecule and the inhaler. On the one hand, even with a good inhalation technique, as in the clinical scenario that we propose, the patient may feel more comfortable using another inhaler and may handle the device better, which potentially results in a better effectiveness. On the other hand, more importantly, we know that the response to inhaled drugs is individualized. ${ }^{46,47}$ For instance, it has been shown that some patients respond better to a long-acting $\beta$ agonist (LABA) or a long-acting muscarinic antagonist (LAMA), and that some patients respond better to one specific $\mathrm{LABD}$ than other in the same family. ${ }^{47}$ It would therefore be logical, to seek a greater therapeutic response, to propose a change in the molecule. This approach has been recognized as a possibility in recent versions of the GOLD documents. ${ }^{5}$ Although in this document the authors apply this concept to double bronchodilator therapy, the same phenomenon also occurs with single bronchodilation ${ }^{48,49}$ and it is also likely to occur with ICS. ${ }^{50}$

\section{Question 2: Should We Escalate to Another Pharmacological Option?}

If we decide to scale treatment, the second question is whether escalating should be pharmacological or nonpharmacological. Interestingly, the GOLD document recommends the addition of a second bronchodilator as the logical step-up to single-agent bronchodilation. ${ }^{5}$ However, respiratory rehabilitation has been shown to yield relevant clinical benefits to patients with a good efficacy/safety profile. ${ }^{51-56}$ These findings have led clinicians to debate whether a step-up to a second LABD or the implementation of a respiratory rehabilitation program would be the best strategy for a patient with persistent symptoms despite receiving one LABD. Even considering the limitations of pulmonary rehabilitation in practice, ie the availability of resources, the percentage of responders and the long-term effect achieved, ${ }^{57,58}$ evaluating the impact of exercise programs would probably help advance individualized therapy at the patient level better than double bronchodilation. Unfortunately, no clinical trials have addressed this issue, and this uncertainty is yet to be clarified.

\section{Question 3: Which Pharmacological Change is Best for Which Type of Patient?}

The third question involves the best change of pharmacological treatment. As the GOLD document indicates, ${ }^{5}$ this should be closely related to the underlying problem. Thus, patients can be separated into those whose main problem is exacerbations or respiratory symptoms. As a general rule, if the problem is persistent symptoms, the most logical pharmacological option is to add a second bronchodilator. While it is true that the benefits in dyspnea reported by clinical trials comparing the average differences between using two LABD or one do not usually produce clinically relevant results, ${ }^{36}$ the number of patients who achieve significant improvement is normally higher with two LABD. On the other hand, ICS has fewer benefits for dyspnea than LABD (Figure 3). 


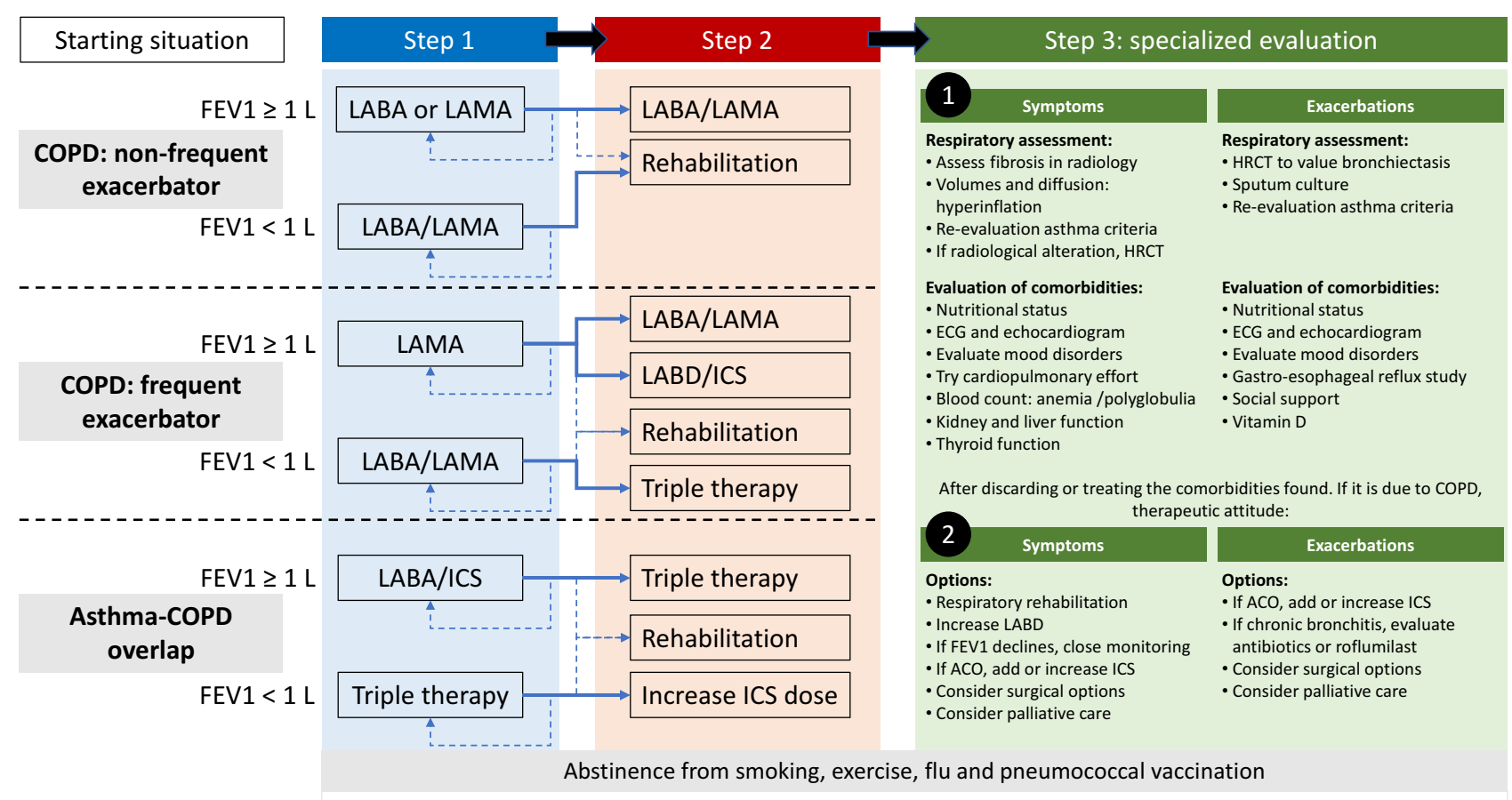

Evaluate compliance, inhalation technique and comorbidities before proceeding to the next step

Figure 3 Complete escalation scheme for stable COPD.

The problem is even more complicated when it comes to patients with persistent exacerbations (Figure 3). In this case, the addition of an ICS appears to reduce the risk of exacerbations and this effect is consistent across all ICS clinical trials. Since the trials of double bronchodilator therapy versus simple bronchodilator therapy have reported an inconsistent reduction in the risk of exacerbations, ${ }^{59-61}$ the first option would probably be to add an ICS. However, when a LABA/ LAMA combination is compared with LABA/ICS, the results are not consistent and probably depend on the type of patient. ${ }^{62}$ Accordingly, there is no consensus about how to define this patient type given the controversy surrounding eosinophils, as commented above. Additionally, when combining a LABD and an ICS, the general recommendation is to associate a LABA with the ICS. This is because there have been few association studies of LAMA with ICS. ${ }^{63-65}$ Notably, the results we do have are promising and it should not be ruled out as a future option. Finally, inhaled triple therapy has represented an advance in the treatment of patients with a high clinical impact, since it allows adherence to be improved at a lower cost, when compared to open triple options. ${ }^{66,67}$ The analysis of the differences in the available triple therapies options has been recently evaluated. ${ }^{66}$

\section{Continuing Escalation: Clinical Approaches for Non-Respondents}

Beyond this point, the escalation of therapies for the patient with persistent high impact despite a correct therapy including good inhalation technique and treatment adherence represents a clinical challenge and requires a specialized respiratory clinic. The best treatment for such complex patients is, therefore, not to continue escalating. In this scenario, the clinician must stop and reevaluate different respiratory and non-respiratory comorbidities that may influence the perceived symptoms and the risk of exacerbations (Figure 3). The problem here is the number of possible conditions that may influence clinical outcomes and the fact that none of the clinical guidelines or recommendation documents show how to implement this approach systematically. This evaluation of comorbidities is key, since none of these comorbid conditions are treated with LABD or ICS, and the approach must therefore be tailor-made for the patient. The number of some of these conditions and diagnostic tests are summarized in Figure 3. Obviously, the priority of one or the other would very much depend on the clinical presentation. Although an evaluation of each of these comorbidities falls beyond of the scope of the present review, ${ }^{68}$ we will now comment a few of them of clinical importance. 
The presence of a chronic bronchial infection in COPD is of special interest. ${ }^{69}$ This clinical situation has been associated with the presence of bronchiectasis. However, recent evidence has shown that COPD patients may have a chronic bronchial infection that causes a major clinical impact and which affects the progression of the disease without the presence of bronchiectasis. ${ }^{70}$ Patients with chronic bronchial infection have increased local and systemic inflammation, more frequent and severe exacerbations and an accelerated progression of the disease. ${ }^{70}$ The possibility of a chronic bronchial infection must be taken into account in all patients with an unfavorable clinical course, even if they do not have purulence in the study in a stable clinical situation. Working groups have recently been created to advise clinicians on how to proceed in patients with COPD and chronic bronchial infection. ${ }^{71}$

The selection of the patient who requires home mechanical ventilation represents another challenge in this type of complex patient. ${ }^{72}$ Although the ventilation/perfusion ratio is probably the most relevant cause of respiratory insufficiency in COPD, at least three different conditions can affect the underlying cause and the response to home mechanical ventilation: obesity and the relation to hypoventilation, muscle function, ${ }^{73}$ and different comorbidities including, most importantly, sleep apnea-hypopnea syndrome and chronic heart failure. ${ }^{74}$ Therefore, there is a need for a systematic thorough evaluation of these patients that helps deciding the best ventilatory strategy. ${ }^{74}$

Finally, other relevant clinical conditions such as mood disorders, vitamin D deficiency, nutritional status, anemia, lung cancer and many others (Figure 3) should be systematically explored and corrected in the persistently highimpact patient with correct inhaled therapy before continuing escalation. If, after a systematic approach, none of these are present or if they are corrected and the patient's symptoms persists, then the options we have to improve the clinical situation are those shown in Figure 3, Point 2, and include pulmonary rehabilitation, increasing the dose of ICS, oral therapies, surgical options and finally palliative care.

Palliative care seeks to prevent or treat symptoms of a disease, the side effects of treatment, and the psychological, social and spiritual problems of patients and their caregivers related to a serious or life-threatening illness or treatment. ${ }^{75}$ Consequently, the goal of such care is not to prolong life expectancy, but to improve its quality. Unfortunately, palliative care is insufficient in COPD, and the lack of medical training and protocols and strategies for $\mathrm{COPD}^{76}$ give $\mathrm{COPD}$ patients less chance of receiving it than cancer patients. ${ }^{77,78}$

\section{Stepping Down in COPD Management}

If the evidence for escalation of treatment is controversial, that for de-escalation is even more so, since there have been fewer de-escalation studies and these are mainly observational in nature. The debate on de-escalation in pharmacological treatment involves two arguments: the withdrawal of one LABD in patients with double bronchodilation therapy and the withdrawal of ICS.

\section{Withdrawal of ICS}

The historical debate to treat COPD was to start with a LAMA or an ICS/LABA combinations. With the introduction of LABA/LAMA combinations the question arose if there was an over-prescription of ICS, which started the discussion and studies of withdrawal of ICS. Since then, the debate over the withdrawal of ICS has generated considerable confusion. First, we must remember that, despite the fact that ICS improve various aspects of COPD, their main use is to reduce the risk of future exacerbations. This means that before a patient with COPD undergoes treatment with ICS, two possible scenarios must be considered, depending on whether or not the patient continues to have exacerbations while receiving ICS.

In the first case, that of a patient who has not had exacerbations in the previous year, various studies have explored the effect of suspending treatment with ICS. Although the initial studies produced confusing results, ${ }^{79-81}$ more recent studies have confirmed the safety of discontinuing ICS in non-exacerbating patients. ${ }^{82,83}$ In the second case, that of a patient who keeps having frequent exacerbations despite receiving ICS, it would initially not be best to advise giving up the ICS. However, one can always argue that the ICS is not doing its job if the patient continues to have exacerbations. In fact, the GOLD document recommends discontinuation if ICS has no effect. ${ }^{5}$ The WISDOM study reported that most of the patients in the study had no exacerbations when the ICS were progressively removed but with differences in different patient types. ${ }^{84}$ It seems therefore that the key factor is the selection of the patient. Previous studies have identified several sub-groups of patients prone to worsening exacerbations after discontinuation of ICS, including women, elderly patients, and smokers. ${ }^{85}$ Additionally, the time of the year was also highlighted as a relevant factor in the discontinuation of ICS. ${ }^{86}$ Interestingly, the WISDOM data revealed that a blood eosinophil count might predict 
a deleterious response to ICS withdrawal. ${ }^{87}$ Despite the ongoing debate about the general use of blood eosinophils as a biomarker for treatment selection (see above), the experiences of this population in this specific clinical context should be explored further. Of note, some studies have shown that approximately $20 \%$ of patients who discontinue the use of ICS have an exacerbation, which occurs within the first 3 months after removal. ${ }^{88}$ Therefore, it seems sensible that, if in doubt, the patient's case should be reviewed soon after to evaluate the clinical effect.

\section{Withdrawal of a LABD}

The debate on whether to discontinue a bronchodilator in patients with double bronchodilator therapy has never been discussed in the literature. Since COPD is a disease which is considered progressive, it would be unwise to recommend a de-escalation for patients with the disease whose symptoms are being controlled well using two bronchodilators. The withdrawal of single or double LABD will probably not be addressed if the treatment option is correctly prescribed to cope with the low reserve these patient experiment. However, with a view to adapting the treatment as much as possible to the individual patient, it would be of interest to conduct clinical studies to evaluate this possibility in specific clinical settings. In this potential scenario, the questions that should be answered include what type of patient should de-escalate and which of the two LABD should be withdrawn first, the LABA or the LAMA. To our knowledge, there are currently no trials evaluating this possibility, so we will have to wait for future developments and research into the use of LABD to answer these questions.

\section{Conclusions}

The escalation and de-escalation of pharmacological treatment in COPD is a challenging dilemma which is affected by many factors. In a strategy of escalation and intensification of treatment, we must bear in mind that: 1) there are individualized responses to different drugs in the same family, 2) the inhalation technique and adherence need to be evaluated before scaling, 3) there are pharmacological and non-pharmacological alternatives to treatment intensification which must be considered together and 4) comorbidities often cause a worsening of the symptoms or affect the clinical expression of the disease. Therefore, the treatment modification scheme must be something more personalized than simply adding molecules, and the therapeutic response and its conditioning factors should be evaluated at each step before proceeding further. Often the best approach is to evaluate the patient correctly prior to deciding on the specific therapeutic approach.

\section{Acknowledgments}

The authors wish to thank Simon Armour from Academia Britanica for his support in improving the English.

\section{Funding}

There is no funding to report.

\section{Disclosure}

JLLC has received grants, honoraria during the last 3 years for lecturing, scientific advice, participation in clinical studies or writing for publications for (alphabetical order): AstraZeneca, Boehringer Ingelheim, Chiesi, CSL Behring, Esteve, Ferrer, Gebro, GlaxoSmithKline, Grifols, Menarini, Novartis, Rovi, and Teva. The other authors declare no conflicts of interest.

\section{References}

1. Soriano JB, Cosio BG, Lopez-Campos JL, Soler-Cataluna JJ, Ancochea J; en nombre del Comite Cientifico Big C. Chronic obstructive pulmonary disease and big data. Arch Bronconeumol. 2021;57(2):144. doi:10.1016/j.arbres.2020.03.029

2. Izquierdo JL, Morena D, Gonzalez Y, et al. Clinical management of COPD in a real-world setting. a big data analysis. Arch Bronconeumol. 2021;57(2):94-100. doi:10.1016/j.arbres.2019.12.025

3. Cabrera Lopez C, Gomez Saenz JT, Molina Paris J, Trigueros Carrero JA, Lopez-Campos JL. Enabling a community approach to respiratory diseases: the HACER COPD project. Arch Bronconeumol. 2020.

4. Lopez-Campos JL, Rodriguez DA, Quintana-Gallego E, MartinezLlorens J, Carrasco Hernandez L, Barreiro E. Ten research questions for improving COPD care in the next decade. COPD. 2019;16(56):311-320. doi:10.1080/15412555.2019.1668919

5. Halpin DMG, Criner GJ, Papi A, et al. Global initiative for the diagnosis, management, and prevention of chronic obstructive lung disease. The 2020 GOLD science committee report on COVID-19 and chronic obstructive pulmonary disease. Am J Respir Crit Care Med. 2021;203(1):24-36. doi:10.1164/rccm.202009-3533SO

6. Miravitlles M, Calle M, Molina J, et al. Spanish COPD Guidelines (GesEPOC) 2021: Updated Pharmacological treatment of stable COPD. Arch Bronconeumol (Engl Ed). 2021:S0300-2896(21)001034. doi:10.1016/j.arbres.2021.03.005.

7. Carrasco Hernandez L, Caballero Eraso C, Ruiz-Duque B, et al. Deconstructing phenotypes in COPD: an analysis of the TRACE cohort. Arch Bronconeumol. 2021. doi:10.1016/j.arbres.2020.12.010

8. Lopez-Campos JL, Centanni S. current approaches for phenotyping as a target for precision medicine in COPD management. COPD. 2018;15(2):108-117. doi:10.1080/15412555.2018.1443064

9. Ancochea J, Soriano JB. COPD in Spain at the start of a new decade. Arch Bronconeumol. 2020.

10. Marott JL, Ingebrigtsen TS, Colak Y, Vestbo J, Lange P. Lung function trajectories leading to chronic obstructive pulmonary disease as predictors of exacerbations and mortality. Am J Respir Crit Care Med. 2020;202(2):210-218. doi:10.1164/rccm.201911-2115OC 
11. Vestbo J, Edwards LD, Scanlon PD, et al. Changes in forced expiratory volume in 1 second over time in COPD. $N$ Engl J Med. 2011;365 (13):1184-1192. doi:10.1056/NEJMoa1105482

12. Mahan V. Clinical trial phases. Int J Clin Med. 2014;05:1374-1383. doi:10.4236/ijcm.2014.521175

13. Donohue JF. Minimal clinically important differences in COPD lung function. COPD. 2005;2(1):111-124. doi:10.1081/COPD-200053377

14. Sedgwick P. Understanding the ecological fallacy. BMJ. 2015;351: h4773. doi:10.1136/bmj.h4773

15. Oude Rengerink K, Thangaratinam S, Barnfield G, et al. How can we teach EBM in clinical practice? An analysis of barriers to implementation of on-the-job EBM teaching and learning. Med Teach. 2011;33 (3):e125-130. doi:10.3109/0142159X.2011.542520

16. Abad-Arranz M, Moran-Rodriguez A, Mascaros Balaguer E, et al. Community Assessment of COPD Health Care (COACH) study: a clinical audit on primary care performance variability in COPD care. BMC Med Res Methodol. 2018;18(1):68. doi:10.1186/s12874018-0528-4

17. Lopez-Campos JL, Navarrete BA, Soriano JB, et al. Determinants of medical prescriptions for COPD care: an analysis of the EPOCONSUL clinical audit. Int J Chron Obstruct Pulmon Dis. 2018;13:2279-2288. doi:10.2147/COPD.S160842

18. Calle Rubio M, Alcazar navarrete B, Soriano JB, et al. Clinical audit of COPD in outpatient respiratory clinics in Spain: the EPOCONSUL study. Int $J$ Chron Obstruct Pulmon Dis. 2017;12:417-426. doi:10.2147/COPD.S124482

19. Fernandez-Villar A, Fernandez-Garcia S, Represas-Represas C. Is the social component of chronic obstructive pulmonary disease a treatable trait? Arch Bronconeumol. 2020;56(4):199-200. doi:10. 1016/j.arbr.2019.06.016

20. Fernandez-Villar A, Soriano JB, Lopez-Campos JL. Overdiagnosis of COPD: precise definitions and proposals for improvement. Br J Gen Pract. 2017;67(657):183-184. doi:10.3399/ bjgp17X690389

21. Schermer TR, Robberts B, Crockett AJ, et al. Should the diagnosis of COPD be based on a single spirometry test? NPJ Prim Care Respir Med. 2016;26:16059. doi:10.1038/npjpcrm.2016.59

22. Hardin M, Cho M, McDonald ML, et al. The clinical and genetic features of COPD-asthma overlap syndrome. Eur Respir J. 2014;44 (2):341-350. doi:10.1183/09031936.00216013

23. Nakawah MO, Hawkins C, Barbandi F. Asthma, chronic obstructive pulmonary disease (COPD), and the overlap syndrome. $J$ Am Board Fam Med. 2013;26(4):470-477. doi:10.3122/jabfm.2013.04.120256

24. Song JH, Lee CH, Kim DK, et al. Differences in prevalence of asthma-COPD overlap according to different criteria. Medicine (Baltimore). 2018;97(36):e12049. doi:10.1097/MD.0000000000012 049

25. Fernandez-Villar A, Lopez-Campos JL. Mixed COPD-asthma phenotype: ACOS or CAOS? A reflection on recent guidelines and recommendations. Arch Bronconeumol. 2016;52(5):277-278. doi:10. 1016/j.arbr.2016.03.002

26. Soler-Cataluna JJ, Novella L, Soler C, et al. Clinical characteristics and risk of exacerbations associated with different diagnostic criteria of asthma-COPD overlap. Arch Bronconeumol. 2020;56(5):282-290. doi:10.1016/j.arbr.2020.03.003

27. Miravitlles M, Soler-Cataluna JJ. GOLD in 2017: a view from the Spanish COPD guidelines (GesCOPD). Arch Bronconeumol. 2017;53 (3):89-90. doi:10.1016/j.arbres.2017.01.001

28. Miravitlles M, Monteagudo M, Solntseva I, Alcazar B. Blood eosinophil counts and their variability and risk of exacerbations in COPD: a population-based study. Arch Bronconeumol. 2021;57 (1):13-20. doi:10.1016/j.arbres.2019.12.015

29. Albertson TE, Chenoweth JA, Pearson SJ, Murin S. The pharmacological management of asthma-chronic obstructive pulmonary disease overlap syndrome (ACOS). Expert Opin Pharmacother. 2020;21 (2):213-231. doi:10.1080/14656566.2019.1701656
30. Proboszcz M, Mycroft K, Paplinska-Goryca M, et al. Relationship between blood and induced sputum eosinophils, bronchial hyperresponsiveness and reversibility of airway obstruction in mild-tomoderate chronic obstructive pulmonary disease. COPD. 2019;16 (5-6):354-361. doi:10.1080/15412555.2019.1675150

31. Singh D, Wedzicha JA, Siddiqui S, et al. Blood eosinophils as a biomarker of future COPD exacerbation risk: pooled data from 11 clinical trials. Respir Res. 2020;21(1):240. doi:10.1186/s12931-02001482-1

32. Calverley PMA, Tetzlaff K, Vogelmeier C, et al. Eosinophilia, frequent exacerbations, and steroid response in chronic obstructive pulmonary disease. Am J Respir Crit Care Med. 2017;196 (9):1219-1221. doi:10.1164/rccm.201612-2525LE

33. Shin SH, Park HY, Kang D, et al. Serial blood eosinophils and clinical outcome in patients with chronic obstructive pulmonary disease. Respir Res. 2018;19(1):134. doi:10.1186/s12931-018-0840-x

34. Alcazar-Navarrete B, Ruiz Rodriguez O, Conde Baena P, Romero Palacios PJ, Agusti A. Persistently elevated exhaled nitric oxide fraction is associated with increased risk of exacerbation in COPD. Eur Respir J. 2018;51(1):1701457. doi:10.1183/13993003.014572017

35. Alcazar-Navarrete B, Castellano Minan F, Santiago Diaz P, Ruiz Rodriguez O, Romero Palacios PJ. Alveolar and bronchial nitric oxide in chronic obstructive pulmonary disease and asthma-COPD overlap. Arch Bronconeumol. 2018;54(8):414-419. doi:10.1016/j. arbr.2018.06.007

36. Lopez-Campos JL, Calero-Acuna C, Marquez-Martin E, et al. Double bronchodilation in chronic obstructive pulmonary disease: a crude analysis from a systematic review. Int J Chron Obstruct Pulmon Dis. 2017;12:1867-1876. doi:10.2147/COPD.S132962

37. Huang TH, Hsiue TR, Lin SH, Liao XM, Su PL, Chen CZ. Comparison of different staging methods for COPD in predicting outcomes. Eur Respir J. 2018;51(3):1700577. doi:10.1183/139930 03.00577-2017

38. Coton S, Vollmer WM, Bateman E, et al. Severity of airflow obstruction in Chronic Obstructive Pulmonary Disease (COPD): proposal for a new classification. COPD. 2017;14(5):469-475. doi:10.1080/ 15412555.2017.1339681

39. Donohue JF, Fogarty C, Lotvall J, et al. Once-daily bronchodilators for chronic obstructive pulmonary disease: indacaterol versus tiotropium. Am J Respir Crit Care Med. 2010;182(2):155-162. doi:10.1164/rccm.200910-1500OC

40. Vogelmeier C, Hederer B, Glaab T, et al. Tiotropium versus salmeterol for the prevention of exacerbations of COPD. $N$ Engl J Med. 2011;364(12):1093-1103. doi:10.1056/NEJMoa1008378

41. Mathioudakis AG, Vestbo J, Singh D. Long-acting bronchodilators for chronic obstructive pulmonary disease: which one(s), how, and when? Clin Chest Med. 2020;41(3):463-474. doi:10.1016/j.ccm.2020.05.005

42. Miravitlles M, Sliwinski P, Rhee CK, et al. Changes in control status of COPD over time and their consequences: a prospective international study. Arch Bronconeumol. 2021;57(2):122-129. doi:10.1016/j. arbres.2020.06.003

43. Koreny M, Demeyer H, Benet M, et al. Patterns of physical activity progression in patients with COPD. Arch Bronconeumol. 2020.

44. Plaza V, Fernandez C, Curto E, et al. Therapeutic adherence of COPD patients according to the involvement levels in health education in their centers. Arch Bronconeumol. 2020.

45. Calle Rubio M, Lopez-Campos JL, Soler-Cataluna JJ, et al. Variability in adherence to clinical practice guidelines and recommendations in COPD outpatients: a multi-level, cross-sectional analysis of the EPOCONSUL study. Respir Res. 2017;18(1):200. doi:10.1186/s12931-017-0685-8

46. Donohue JF, Singh D, Munzu C, Kilbride S, Church A. Magnitude of umeclidinium/vilanterol lung function effect depends on monotherapy responses: results from two randomised controlled trials. Respir Med. 2016;112:65-74. doi:10.1016/j.rmed.2016.01.001 
47. Feldman GJ, Sousa AR, Lipson DA, et al. Comparative efficacy of once-daily umeclidinium/vilanterol and tiotropium/olodaterol therapy in symptomatic chronic obstructive pulmonary disease: a randomized study. Adv Ther. 2017;34(11):2518-2533. doi:10.1007/s12325-0170626-4

48. Feldman G, Maltais F, Khindri S, et al. A randomized, blinded study to evaluate the efficacy and safety of umeclidinium $62.5 \mu \mathrm{g}$ compared with tiotropium $18 \mu \mathrm{g}$ in patients with COPD. Int J Chron Obstruct Pulmon Dis. 2016;11:719-730. doi:10.2147/COPD.S102494

49. Dahl R, Chung KF, Buhl R, et al. Efficacy of a new once-daily long-acting inhaled beta2-agonist indacaterol versus twice-daily formoterol in COPD. Thorax. 2010;65(6):473-479. doi:10.1136/ thx.2009.125435

50. Postma DS, Roche N, Colice G, et al. Comparing the effectiveness of small-particle versus large-particle inhaled corticosteroid in COPD. Int J Chron Obstruct Pulmon Dis. 2014;9:1163-1186. doi:10.2147/ COPD.S68289

51. Paneroni M, Simonelli C, Vitacca M, Ambrosino N. Aerobic exercise training in very severe chronic obstructive pulmonary disease: a systematic review and meta-analysis. Am J Phys Med Rehabil. 2017;96(8):541-548. doi:10.1097/PHM.0000000000000667

52. Moore E, Newson R, Joshi M, et al. Effects of pulmonary rehabilitation on exacerbation number and severity in people with COPD: an historical cohort study using electronic health records. Chest. 2017;152:1188-1202. doi:10.1016/j.chest.2017.05.006

53. Maddocks M, Delogu V, Jones SE, Polkey MI, Man WD. Exercise training versus neuromuscular stimulation in severe chronic obstructive pulmonary disease. Arch Bronconeumol. 2017;53(7):357-359. doi:10.1016/j.arbres.2016.11.022

54. Raskin J, Marks T, Miller A. Phenotypes and characterization of COPD: a pulmonary rehabilitation perspective. $J$ Cardiopulm Rehabil Prev. 2017.

55. Barreiro E. Skeletal muscle dysfunction in COPD: novelties in the last decade. Arch Bronconeumol. 2017;53(2):43-44. doi:10.1016/j. arbres.2016.07.009

56. Pleguezuelos E, Guirao L, Moreno E, et al. Safety of rehabilitation program for COPD patients. Arch Bronconeumol. 2017;54:111-112. doi:10.1016/j.arbres.2017.06.012

57. Wouters EFM, Wouters B, Augustin IML, Houben-Wilke S, Vanfleteren L, Franssen FME. Personalised pulmonary rehabilitation in COPD. Eur Respir Rev. 2018;27:147. doi:10.1183/16000617.0125-2017

58. Milner SC, Boruff JT, Beaurepaire C, Ahmed S, Janaudis-Ferreira T. Rate of, and barriers and enablers to, pulmonary rehabilitation referral in COPD: a systematic scoping review. Respir Med. 2018;137:103-114. doi:10.1016/j.rmed.2018.02.021

59. Calverley PMA, Anzueto AR, Carter K, et al. Tiotropium and olodaterol in the prevention of chronic obstructive pulmonary disease exacerbations (DYNAGITO): a double-blind, randomised, parallel-group, active-controlled trial. Lancet Respir Med. 2018;6 (5):337-344. doi:10.1016/S2213-2600(18)30102-4

60. Wedzicha JA, Buhl R, Singh D, et al. Tiotropium/olodaterol decreases exacerbation rates compared with tiotropium in a range of patients with COPD: pooled analysis of the $\operatorname{TONADO}((\mathrm{R})) /$ DYNAGITO((R)) trials. Adv Ther. 2020;37(10):4266-4279. doi:10. 1007/s12325-020-01438-3

61. Wedzicha JA, Decramer M, Ficker JH, et al. Analysis of chronic obstructive pulmonary disease exacerbations with the dual bronchodilator QVA149 compared with glycopyrronium and tiotropium (SPARK): a randomised, double-blind, parallel-group study. Lancet Respir Med. 2013;1(3):199-209. doi:10.1016/S2213-2600(13)70052-3

62. Soler-Cataluna JJ, Miralles C. Exacerbation syndrome in COPD: a paradigm shift. Arch Bronconeumol. 2020.

63. Lee L, Kerwin E, Collison K, et al. The effect of umeclidinium on lung function and symptoms in patients with fixed airflow obstruction and reversibility to salbutamol: a randomised, 3-phase study. Respir Med. 2017;131:148-157. doi:10.1016/j.rmed.2017.08.013
64. Perng DW, Tao CW, Su KC, Tsai CC, Liu LY, Lee YC. Antiinflammatory effects of salmeterol/fluticasone, tiotropium/fluticasone or tiotropium in COPD. Eur Respir J. 2009;33(4):778-784. doi:10. 1183/09031936.00115308

65. Um SW, Yoo CG, Kim YW, Han SK, Shim YS. The combination of tiotropium and budesonide in the treatment of chronic obstructive pulmonary disease. J Korean Med Sci. 2007;22(5):839-845. doi:10. 3346/jkms.2007.22.5.839

66. Lopez-Campos JL, Carrasco-Hernandez L, Roman Rodriguez L, Quintana-Gallego E, Carmona Bernal C, Alcazar Navarrete B. The clinical implications of triple therapy in fixed-dose combination in COPD: from the trial to the patient. Arch Bronconeumol. 2020;56 (4):242-248. doi:10.1016/j.arbr.2020.02.002

67. Celli B, Divo M, Plata VP. Pharmacotherapy impacts on COPD mortality. Arch Bronconeumol. 2021;57(1):5-6. doi:10.1016/j.arbres. 2020.03.030

68. Lopez-Campos JL, Ruiz-Duque B, Carrasco-Hernandez L, CaballeroEraso C. Integrating comorbidities and phenotype-based medicine in patient-centered medicine in COPD. J Clin Med. 2020;9(9):2745. doi:10.3390/jcm9092745

69. de la Rosa Carrillo D, Lopez-Campos JL, Alcazar Navarrete B, et al. Consensus document on the diagnosis and treatment of chronic bronchial infection in chronic obstructive pulmonary disease. Arch Bronconeumol. 2020;56(10):651-664. doi:10.1016/j.arbres.2020.04.023

70. Matkovic Z, Miravitlles M. Chronic bronchial infection in COPD. Is there an infective phenotype? Respir Med. 2013;107(1):10-22. doi:10.1016/j.rmed.2012.10.024

71. Lopez-Campos JL, Miravitlles M, de la Rosa Carrillo D, Canton R, SolerCataluna JJ, Martinez-Garcia MA. Current challenges in chronic bronchial infection in patients with chronic obstructive pulmonary disease. J Clin Med. 2020;9(6):1639. doi:10.3390/jcm9061639

72. Lujan M, Ergan B. Guidelines for chronic non-invasive ventilation in COPD: from experience to evidence. Arch Bronconeumol. 2020.

73. Cruthirds CL, van der Meij BS, Wierzchowska-McNew A, Deutz NEP, Engelen M. Presence or absence of skeletal muscle dysfunction in chronic obstructive pulmonary disease is associated with distinct phenotypes. Arch Bronconeumol. 2020;57:264-272. doi:10.1016/j.arbres.2019.12.034

74. Lopez-Campos JL, Caballero-Eraso C, Barrot-Cortes E. Home mechanical ventilation for stable COPD in GOLD 2017: what are we ventilating? Respirology. 2017;22(8):1497-1499. doi:10.1111/resp.13091

75. Curtis JR. Palliative and end-of-life care for patients with severe COPD. Eur Respir J. 2008;32(3):796-803. doi:10.1183/09031936.00126107

76. Ecenarro PS, Iguiniz MI, Tejada SP, et al. Management of COPD in end-of-life care by Spanish pulmonologists. COPD. 2018;15 (2):171-176. doi:10.1080/15412555.2018.1441274

77. Gore JM, Brophy CJ, Greenstone MA. How well do we care for patients with end stage chronic obstructive pulmonary disease (COPD)? A comparison of palliative care and quality of life in COPD and lung cancer. Thorax. 2000;55(12):1000-1006. doi:10. 1136/thorax.55.12.1000

78. Au DH, Udris EM, Fihn SD, McDonell MB, Curtis JR. Differences in health care utilization at the end of life among patients with chronic obstructive pulmonary disease and patients with lung cancer. Arch Intern Med. 2006;166(3):326-331. doi:10.1001/ archinte.166.3.326

79. van der Valk P, Monninkhof E, van der Palen J, Zielhuis G, van Herwaarden C. Effect of discontinuation of inhaled corticosteroids in patients with chronic obstructive pulmonary disease: the COPE study. Am J Respir Crit Care Med. 2002;166(10):1358-1363. doi:10.1164/ rccm.200206-512OC

80. Wouters EF, Postma DS, Fokkens B, et al. Withdrawal of fluticasone propionate from combined salmeterol/fluticasone treatment in patients with COPD causes immediate and sustained disease deterioration: a randomised controlled trial. Thorax. 2005;60(6):480-487. doi:10.1136/thx.2004.034280 
81. Nadeem NJ, Taylor SJ, Eldridge SM. Withdrawal of inhaled corticosteroids in individuals with COPD--a systematic review and comment on trial methodology. Respir Res. 2011;12(1):107. doi:10.1186/ 1465-9921-12-107

82. Rossi A, Guerriero M, Corrado A; Group OAS. Withdrawal of inhaled corticosteroids can be safe in COPD patients at low risk of exacerbation: a real-life study on the appropriateness of treatment in moderate COPD patients (OPTIMO). Respir Res. 2014;15:77. doi:10.1186/1465-9921-15-77

83. Greulich T, Kostikas K, Gaga M, et al. Indacaterol/glycopyrronium reduces the risk of clinically important deterioration after direct switch from baseline therapies in patients with moderate COPD: a post hoc analysis of the CRYSTAL study. Int J Chron Obstruct Pulmon Dis. 2018;13:1229-1237. doi:10.2147/COPD.S159732

84. Magnussen H, Watz H, Kirsten A, et al. Stepwise withdrawal of inhaled corticosteroids in COPD patients receiving dual bronchodilation: WISDOM study design and rationale. Respir Med. 2014;108 (4):593-599. doi:10.1016/j.rmed.2014.01.002
85. Schermer TR, Hendriks AJ, Chavannes NH, et al. Probability and determinants of relapse after discontinuation of inhaled corticosteroids in patients with COPD treated in general practice. Prim Care Respir J. 2004;13(1):48-55. doi:10.1016/j.pcrj.2003.11.005

86. Liesker JJ, Bathoorn E, Postma DS, Vonk JM, Timens W, Kerstjens HA. Sputum inflammation predicts exacerbations after cessation of inhaled corticosteroids in COPD. Respir Med. 2011;105(12):1853-1860. doi:10.1016/j.rmed.2011.07.002

87. Watz H, Tetzlaff K, Wouters EF, et al. Blood eosinophil count and exacerbations in severe chronic obstructive pulmonary disease after withdrawal of inhaled corticosteroids: a post-hoc analysis of the WISDOM trial. Lancet Respir Med. 2016;4(5):390-398. doi:10. 1016/S2213-2600(16)00100-4

88. Karner C, Cates CJ. The effect of adding inhaled corticosteroids to tiotropium and long-acting beta(2)-agonists for chronic obstructive pulmonary disease. Cochrane Database Syst Rev. 2011;(9): CD009039.

\section{Publish your work in this journal}

The International Journal of COPD is an international, peer-reviewed journal of therapeutics and pharmacology focusing on concise rapid reporting of clinical studies and reviews in COPD. Special focus is given to the pathophysiological processes underlying the disease, intervention programs, patient focused education, and self management protocols. This journal is indexed on PubMed Central, MedLine and CAS. The manuscript management system is completely online and includes a very quick and fair peer-review system, which is all easy to use. Visit http://www.dovepress.com/testimonials.php to read real quotes from published authors. 